\title{
Article
}

\section{Static and Dynamic Testing of Sei Dareh Cable-Stayed Bridge West Sumatera, Indonesia}

\author{
Sumargo $^{*}$, Afdhal Lazuardiansyah Ramdhani ${ }^{2}$ \\ 1 Universitas Jenderal Achmad Yani; sumargo@lecture.unjani.ac.id \\ 2 Politeknik Negeri Bandung; afdhal.lazuardiansyah.mtri19@polban.ac.id
}

\begin{abstract}
The Sei Dareh Bridge is a cable-stayed bridge located in West Sumatra Province, Indonesia. The bridge, has a main span of 123 meters length and 9 meters wide, crosses the Batanghari River. Traffic load is transmitted through 4 prestressed cables to a 42.4 meter high pylon made of concrete. Bridge deck and traffic loads are directly supported by steel box girders as main beams that are reinforced laterally with cross beams IWF 800.300.16.24 and stringers IWF 350.350.12.19. This paper discusses static and dynamic testing on the bridge which aims to assess the feasibility before it is opened for public. Based on the test, it was concluded that the $73 \%$ static load could not be achieved because the deflection that occurred was beyond the allowable deflection. This is exacerbated by the sound of a loud clanging sound on the ST2-X1 prestressed cable when loading to 240 tons or $58 \%$ of the targeted load. In addition, this bridge is included in the "lazy bridge" category because it takes 24 hours to return to an undeformed condition after loading. As a recommendation for this bridge, it is necessary to carry out a structural health monitoring system (SHMS) regularly on the vehicle floor and cables.
\end{abstract}

Keywords: Structural health monitoring; bridge load testing; dynamic testing; operational modal analysis; experimental modal analysis

\section{Introduction}

A cable stayed bridge is one type of long span bridge where prestressed cable elements act as the main element in bearing the load of the girder and floor deck. The use of this system will certainly reduce the weight of the bridge structure significantly. This bridge became widely used after the construction of the Stromsung Bridge in Sweden in 1955 with a main span of 182.6 meters [1]. In Indonesia, this type of bridge began to be widely used after the construction of the Barelang Bridge at Batam Island in 1992 and was completed in 1998, which has a main span of 245 meters. In fact, currently in Banjarmasin, South Kalimantan Indonesia is being built the first cable stayed bridge with curved geometry in Indonesia with a main span of 300 meters.

The longer the span of the bridge and the increasingly varied bridge geometry causes the bridge's behavior due to dynamic loads such as earthquakes, wind and traffic to become more complicated, thus requires a special study [2]. Therefore, load testing in the field can be a method to determine bridge behavior. The test can be carried out either statically or dynamically according to the data requirements required..

Dynamic and static load testing on cable stayed bridges has been carried out by previous researchers. The Vasco da Gama bridge (Italy) was studied by Cunha, et al [3] to determine the dynamic behavior of the bridge by conducting free vibration test and ambient vibration test. Based on this test, it is concluded that there is a good correlation between the results of field testing and the 3-dimensional finite element model created during the design stage. The same thing was done by Ren at al [4] on the Qingzhou Bridge (China) and Bayraktar et al [2] on the Nissibi Bridge (Turkey). Meanwhile, Fang, et al [5] only carried out a static load test of the Kao-Ping-Hsi (China) bridge before it was opened to traffic. There were 40 loading schemes carried out, including the effect of bending and 
torsion and the effect of temperature changes on the main girder deflection. Likewise, $\mathrm{Ni}$ et al [6] who only carried out dynamic testing of the Sutong Bridge (China) using a method called Bayesian. The Bayesian method is a logic of probability that provides a rigorous framework for identifying and calculating model uncertainty. This method is an effective way to analyze and collect data in ambient conditions effective way to analyze and collect data in ambient conditions.

A series of dynamic or static tests are often carried out before the bridge is opened to traffic, because this is related to road function-worthy requirements as stated in the Minister of Public Works Regulation concerning Procedures and Requirements for Road Function-Worthy. Santoso [7] once conducted an assessment of the condition of the Kalikuto Bridge with a steel curved arc structure for eligibility requirements with a vibration test. Likewise, what has been done by Setiati et al [8] on the Sinapeul Bridge with a fully integral structure. Thus, this paper will discuss the static and dynamic load test on the Sei Dareh cable stayed bridge in West Sumatra Province was carried out in 2019.

\section{The Sei Dareh Cable Stayed Bridge}

\subsection{Tested bridge}

The Sei Dareh Cable Stayed Bridge is a new bridge built next to the existing bridge which is intended to unravel the congestion of road traffic. The bridge that divides the Batang Hari River has a bridge length and width, traffic width and pylon height, respectively, 123, 9, 7, and 42.4 meters. The main girder on the floor structure of the bridge uses a steel box section, while the transverse and longitudinal girder uses IWF steel sections with a minimum yield and breaking stress of $490 \mathrm{MPa}$ and $610 \mathrm{MPa}$, respectively. The quality of the concrete used in the pylon is $30 \mathrm{MPa}$. In addition, the prestressed cables has a modulus of elasticity of $195000 \mathrm{MPa}$ and A416-270 material are used (normal relaxation strand). Figure 1 shows a map of bridge location and aerial photo. Figure 2 shows a photo of the Sei Dareh Bridge accompanied by an explanation of some of the bridge elements. This bridge is carried out in two types of testing, namely static testing and dynamic testing. Both of them have their respective objectives and testing methods like in the next section.

In general, the load test on this bridge begins with a visual inspection which aims to ensure that the structural components are properly installed and ready to be loaded, such as bolts between joints, stay cables and so on. Then the static and dynamic load testing is carried out and then ends with a final visual inspection.

Based on the visual inspection that was carried out right before the test, it was found that all the conditions of the structural elements were in good condition, it was just that there were cracks as big as the contents of the pen on the pylon foot of the bridge as in Figure 3

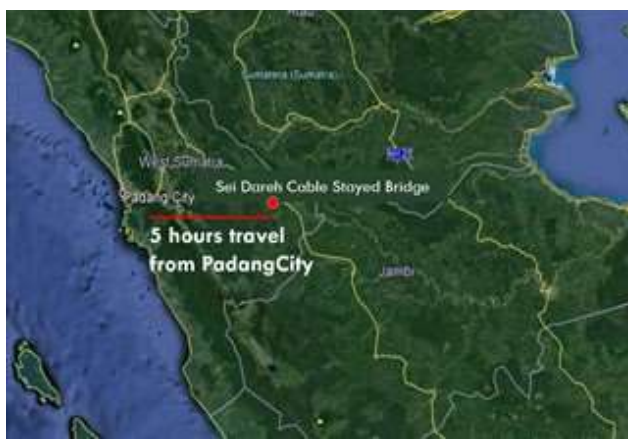

(a)

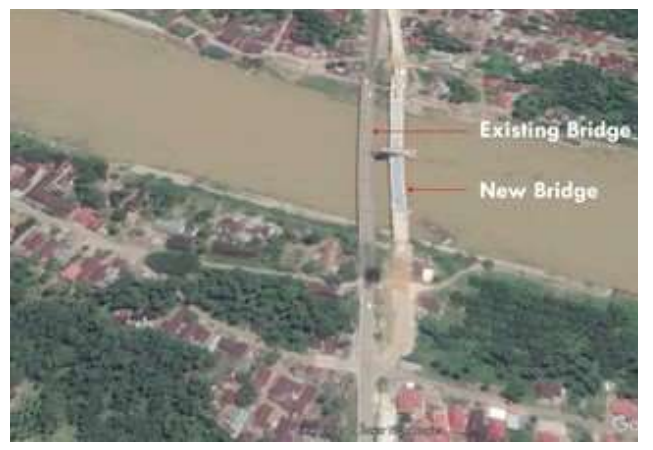

(b)

Figure 1. (a) Location map of Sei Dareh Cable Stayed Bridge; (b) Aerial photo of the new bridge and existing bridge of Sei Dareh 


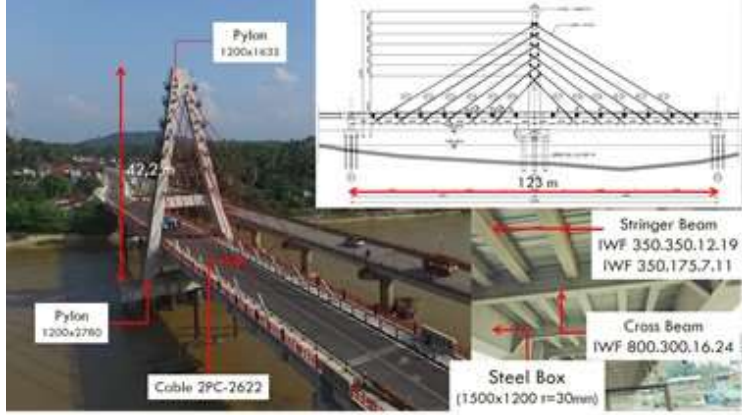

(a)

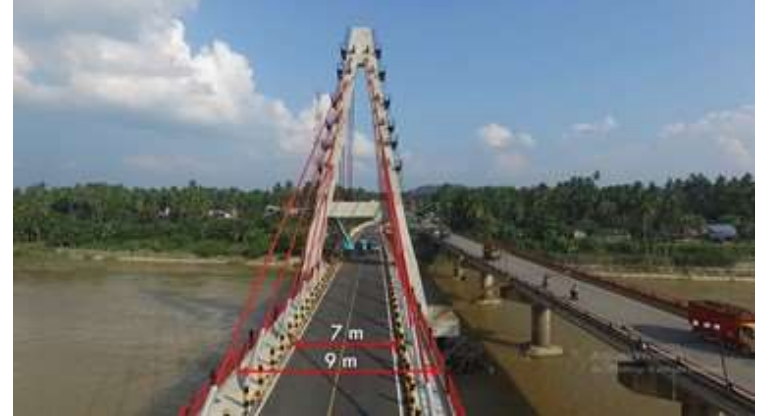

(b)

Figure 2. (a) Element of Sei Dareh Cable Stayed Bridge; (b) Aerial photo of Sei Dareh Cable Stayed Bridge

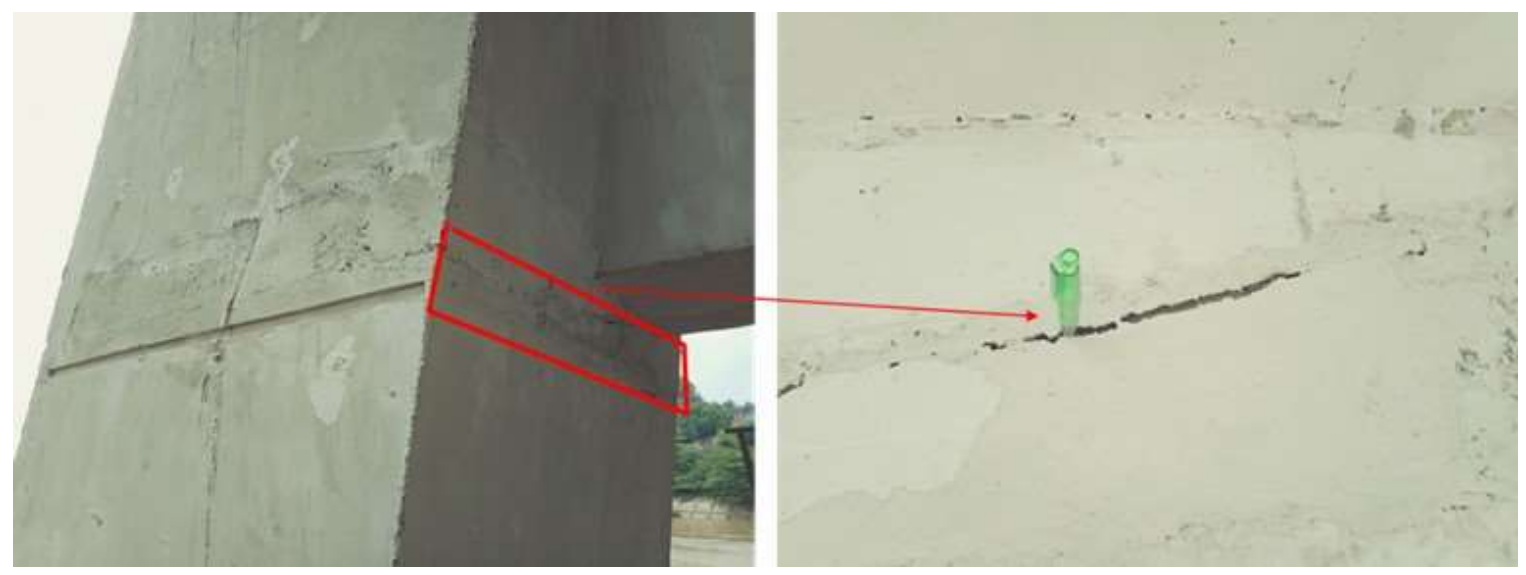

Figure 3. Crack at pylon leg

\subsection{Static load test}

Static testing will produce deflection of the bridge beams under review. Deflection is a change in the shape of the beams in a deformed direction due to a load measured from the initial neutral surface to the neutral surface after the beams are deformed. Indonesian Code SNI: T-03-2005 regarding the design of steel structures for bridges requires that the maximum allowable deflection of bridges is L / 800 span. Bridge static testing refers to SNI: 1725-2016 regarding bridge loading. The code discusses the load for lane "D" which has an uniform distributed load (UDL) depending on the total bridge length loaded L, which is as follows:

$$
\begin{aligned}
& \text { if } \quad \mathrm{L} \leq 30 \mathrm{~m}: \mathrm{q}=9,0 \mathrm{kPa} \\
& \text { if } \quad \mathrm{L}>30 \mathrm{~m}: \mathrm{q}=9,0\left(0,5+\frac{15}{L}\right) \mathrm{kPa}
\end{aligned}
$$

The following is the calculation of the static load that will be charged to the bridge. The length of span $\mathrm{L}=2 \times 61.5 \mathrm{~m}=123$ meters and the vehicle floor width is 7.0 meters which results in vehicle floor area of $(61.5 \mathrm{~m})(7 \mathrm{~m})=430.5 \mathrm{~m} 2$. Since $\mathrm{L}>30$ meters then the UDL, $\mathrm{q}=9.0(0.5+15 / \mathrm{L})=6.70 \mathrm{kPa}=683.2 \mathrm{~kg} / \mathrm{m} 2 \approx 683 \mathrm{~kg} / \mathrm{m} 2$. Loading test should not less than $70 \%$ of UDL: $70 \% \times 683 \mathrm{~kg} / \mathrm{m} 2=478.1 \mathrm{~kg} / \mathrm{m} 2$. Pedestrian live load is $500 \mathrm{~kg} / \mathrm{m} 2$, and the width of the sidewalk is 2 meters on the left and right, then the total width of the sidewalk is 4 meters. Load test on the side walk is $(4 \mathrm{~m})(500 \mathrm{~kg} / \mathrm{m} 2)=2$ tons $/ \mathrm{m} 2 \times 70 \%=$ $1.4 \mathrm{t} / \mathrm{m} 1$ and total pedestrian load test on bridge is $1.4 \mathrm{t} / \mathrm{m} 1 \times 61.5 \mathrm{~m}: 86.1$ tons. Total UDL and pedestrian load test is $(430.5 \mathrm{~m} 2) \times(478.1 \mathrm{~kg} / \mathrm{m} 2)=205.8$ tons +86.1 tons $=291.9 \approx 292$ tons. Use truck with a load of 30 tons including the truck's own weight, which means that the number of trucks in one span is (292 tons/ 30 tons) $\approx 10$ trucks. This truck load is $73 \%$ of the UDL design load. The total need for trucks for span P1-P2-P3 is 20 trucks.

Static testing was carried out by loading the bridge using trucks loaded with sand. There were five static loading schemes carried out on spans P1-P2 and P2-P3 alternately 
with loading stages of 60, 120, 180, 240 and 300 tons. In addition, there were also five other loading schemes that are carried out simultaneously on both spans, namely 120, 240, 360, 480, and 600 tons. The load scheme for the P1-P2 span in the static test is as shown in Figure 5, the same scheme is also applied to the P2-P3 spans and for other schemes, the simultaneous loading is carried out on the P1-P2 and P2-P3 spans. The dimensions and capacity of the trucks used during the test are as shown in Figure 4.

The loading is carried out in stages for both loading and unloading schemes and measuring deflection on the bridge beam using a water pass and total station (TS) measuring device. The use of the two measuring instruments simultaneously aims to mutually validate the two results. The placement of the measuring instrument during the test is shown in Figure 6. The execution of load test as shown like Figure 7.

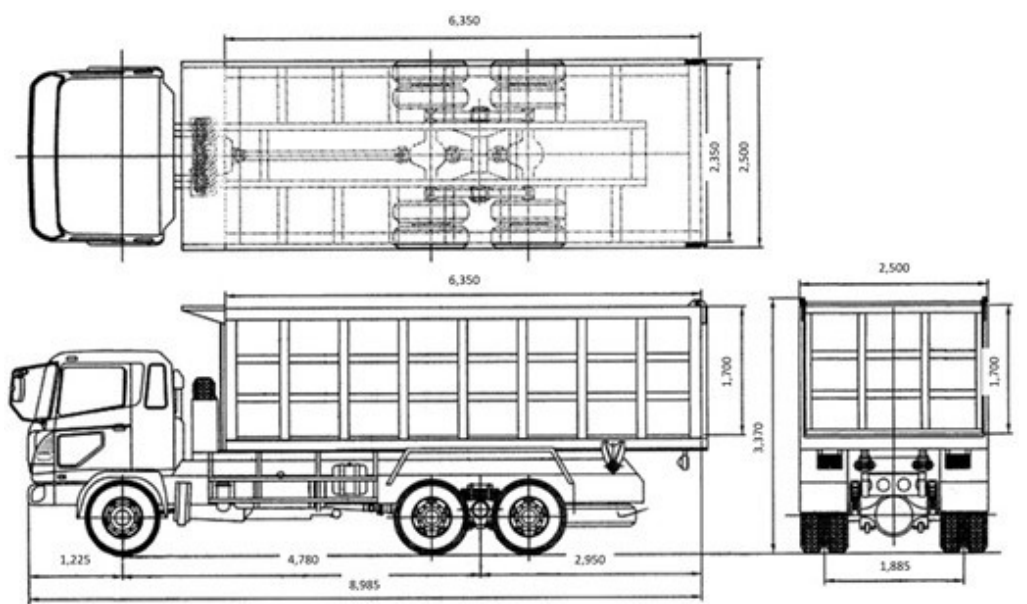

Figure 4. Dimension of truck loaded by sand

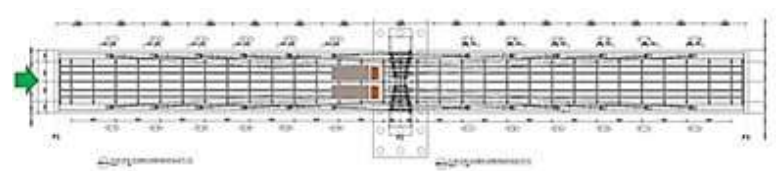

(a)

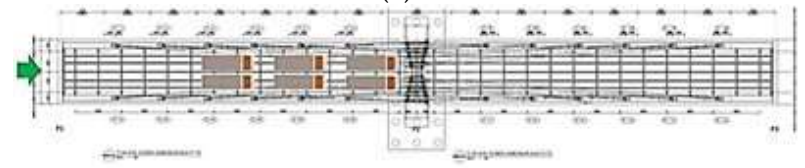

(c)

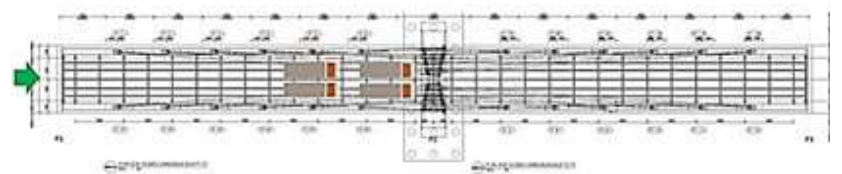

(b)

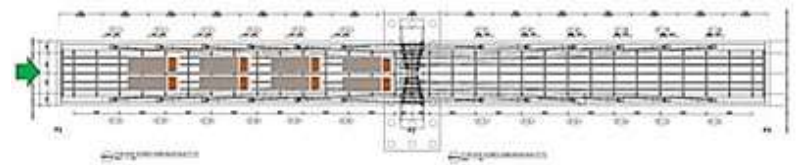

(d)

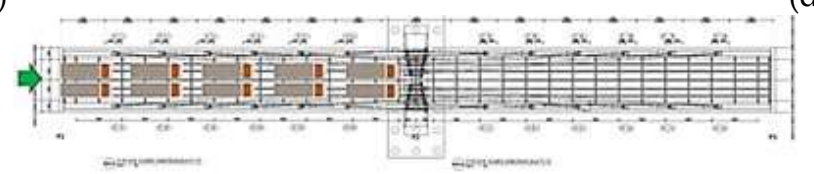

(e)

Figure 5. Load scheme for P1-P2 and also applied at P2-P3, (a) Load 60 tons; (b) Load 120 tons; (c) Load 180 tons; (d) Load 240 tons; (e) Load 600 tons 


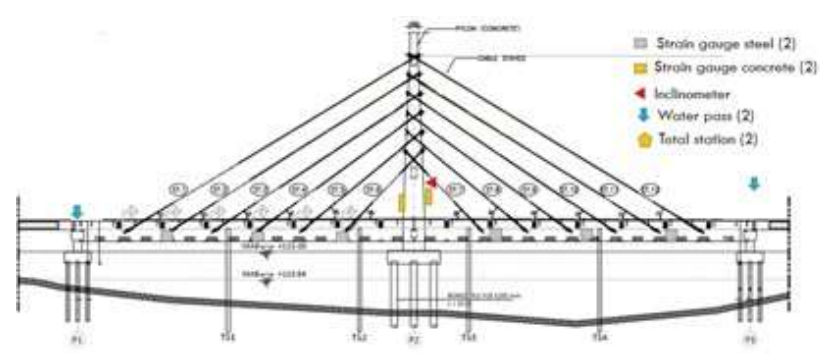

(a)

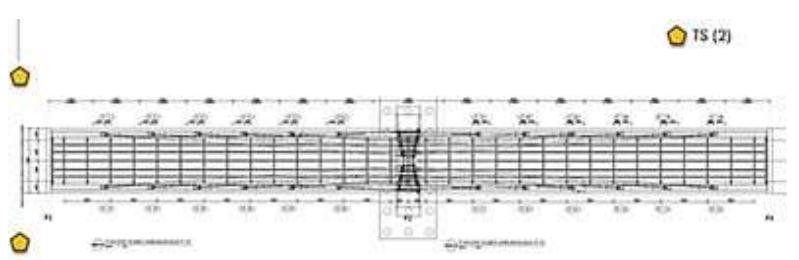

(b)

Figure 6. (a) Placement of strain gauge, inclinometer, and waterpas; (b) Placement of total station

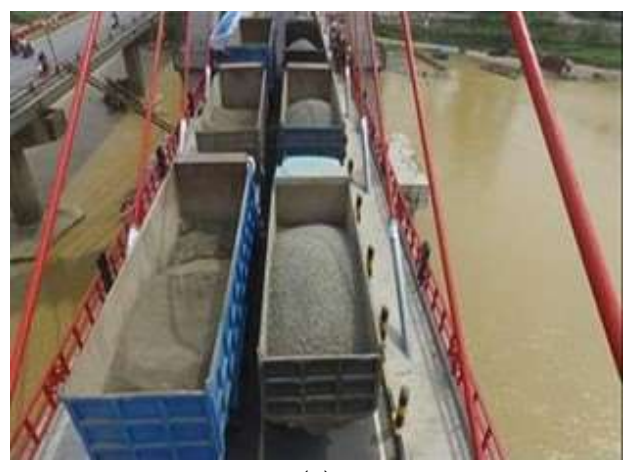

(a)

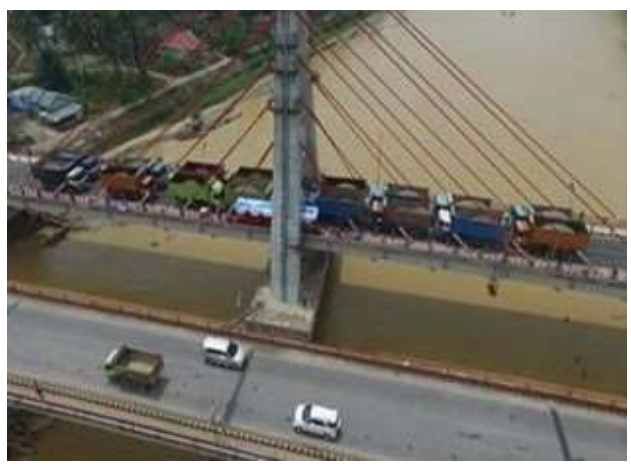

(b)

Figure 7. The execution of static load test

\subsection{Dynamic load test}

The dynamic test is carried out by giving a sudden impact through a truck moving forward from a jumper with a certain dimension. At the same time, the acceleration of the structure is measured using an accelerometer which is placed at several points. The accelerometer installation determination is based on the maximum response value obtained based on modeling in Midas Civil. The illustration of each loading scheme and placement of the accelerometer during dynamic loading is described in Table 1, Figure 8 and Figure 9.

Table 1. Schematic of dynamic load test

\begin{tabular}{|c|c|c|}
\hline Scheme & Load impact position & Position Acceleromenter \\
\hline $1 \mathrm{~A}$ & \multirow{3}{*}{$\mathrm{L} / 2$ of $\mathrm{P} 1-\mathrm{P} 2$} & $\mathrm{~L} / 2$ of $\mathrm{P} 1-\mathrm{P} 2$ \\
\hline 1B & & 3L/4 of P1-P2 \\
\hline $1 \mathrm{C}$ & & Sidewalk of P1-P2 \\
\hline $2 \mathrm{~A}$ & \multirow{3}{*}{$\mathrm{L} / 2$ of $\mathrm{P} 2-\mathrm{P} 3$} & L/2 P2-P3 \\
\hline $2 \mathrm{~B}$ & & 3L/4 P2-P3 \\
\hline $2 \mathrm{C}$ & & Trotoar P2-P3 \\
\hline
\end{tabular}

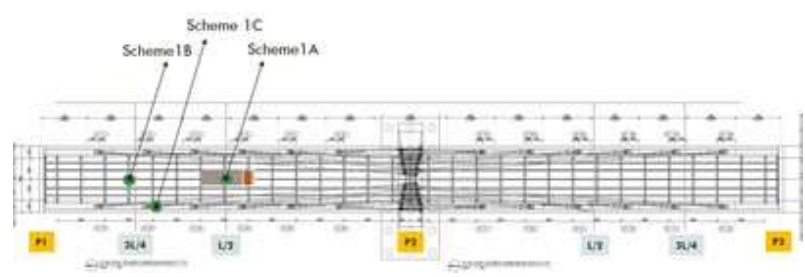

(a)

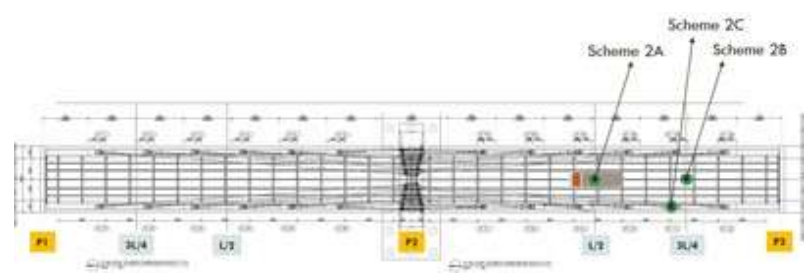

(b)

Figure 8. (a) Schematic type 1; (b) Schematic type 2 


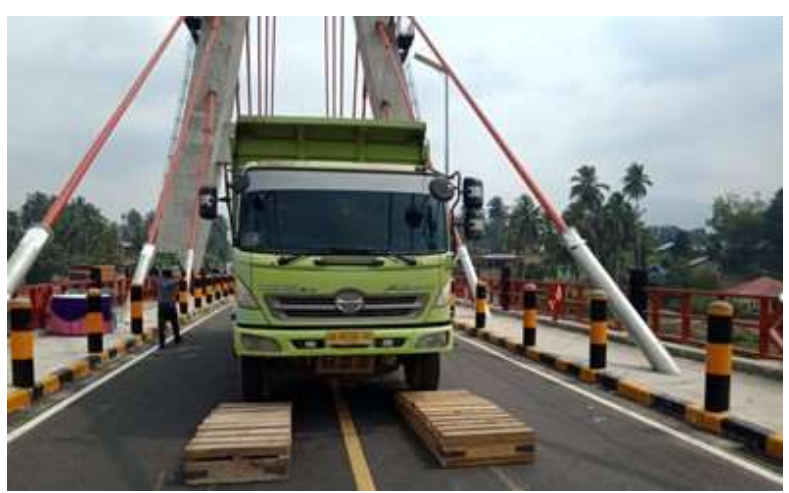

(a)

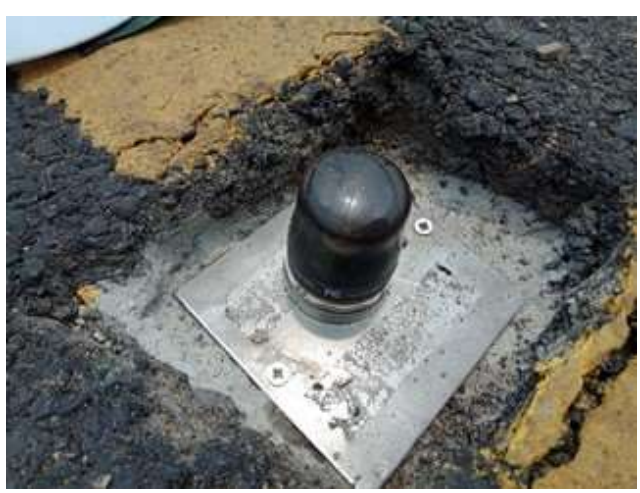

(b)

Figure 9. (a) The execution of dynamic load test; (b) The placement of accelometer

\subsection{Finite element model of bridge}

Sei Dareh Bridge needs to be modeled in 3D with a finite element model. This modeling is intended to compare the theoretical bridge behavior and the bridge behavior in the field test results. In addition, this modeling is also the basis for an inspector to estimate the placement of the measuring instrument during real testing in the field because usually the inspector will place the instrument on the bridge elements that experience the greatest internal force based on the results of 3D analysis. 3D modeling was carried out in the "Midas Civil-2011 v.2.1" program as shown in Figure 10.

Based on the figure, this bridge consists of three components, namely the floor structure, pylons and cables. The floor structure consisting of steel box elements, cross girders and stringers is modeled in the software as beam elements so that these elements can experience bending, shear and axial forces. The same is modeled on the pylon. Meanwhile, the cable component is modeled as a cable-pretension element so that the element can only experience axial tension and the initial tension force of the cable can be adjusted. The base of the pylon is modeled using a clamp positioning which has translation and rotation restraint in all directions. Meanwhile, the placement at both ends of the bridge girder is modeled into two types. The first type, placement has a $z$-axis translational restraint. The second type, placement has translational constraints in the $\mathrm{z}$ and $\mathrm{y}$-axis directions.

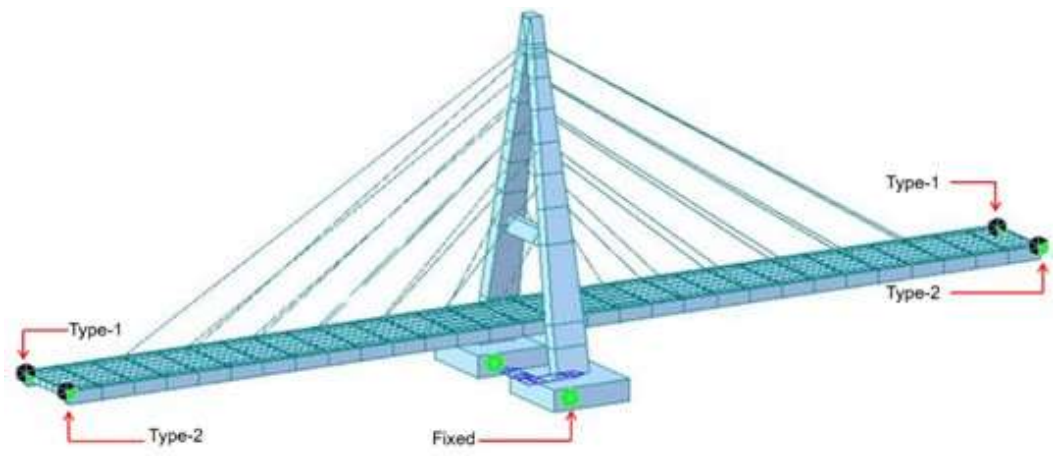

Figure 10. Finite element model of the Sei Dareh Cable Stayed Bridge

\section{Results}

\subsection{Result of static load test}

Some of the results obtained from static testing in the field include the beam deflection as measured by a water pass device and a total station. Beam deflection is measured when the bridge is loading and unloading at spans P1-P2 and P2-P3.

Figures 11 to 14 show the deflection that occurs in the P1-P2 and P2-P3 spans due to truck loading on the P1-P2 span and vice versa which is measured using a water pass and total station. Based on measurements, the deflection that occurs in the fifth stage of 
loading with a load of 240 tons is $55 \mathrm{~mm}$. That is, the deflection that occurs exceeds the allowable deflection of $44,895 \mathrm{~mm}$. At the same time, there was a loud clanging sound from the ST2-X1 cable and the large vibration of the bridge. This caused the Indonesian Bridge and Road Tunnel Safety Commission decided not to continue loading up to 300 tons. In addition, it can be seen from the results of field testing that the amount of deflection at zero loading and unloading has a different value, meaning that the floor of the bridge did not return to its original position after the unloading stage where all loads had been removed. Based on field observations, the beam returned to its original state in its entirety after 24 hours so that this bridge is called a "lazy bridge".

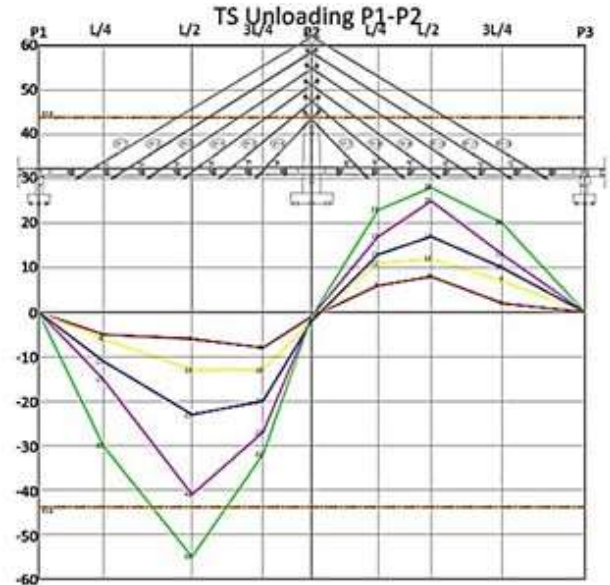

(a)

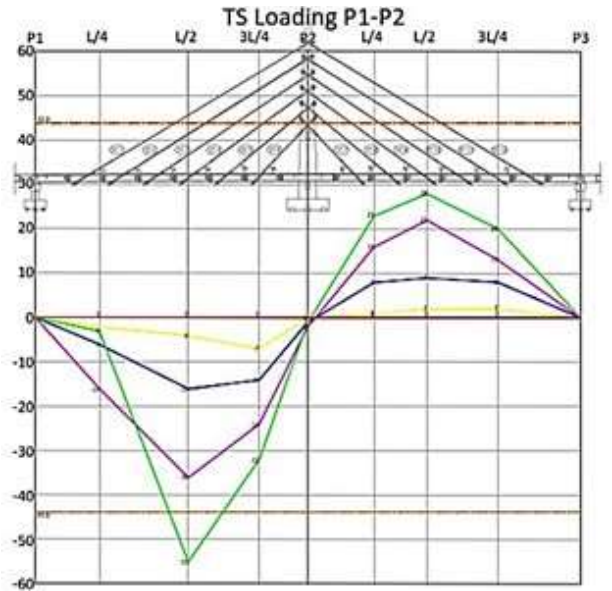

(b)

Figure 11. Graph of deflection measurement with total station when ; a) loading and b) unloading span P1-P2

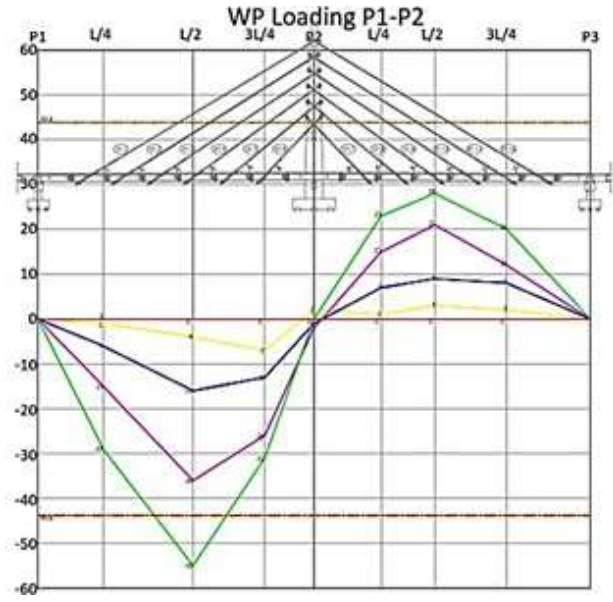

(a)

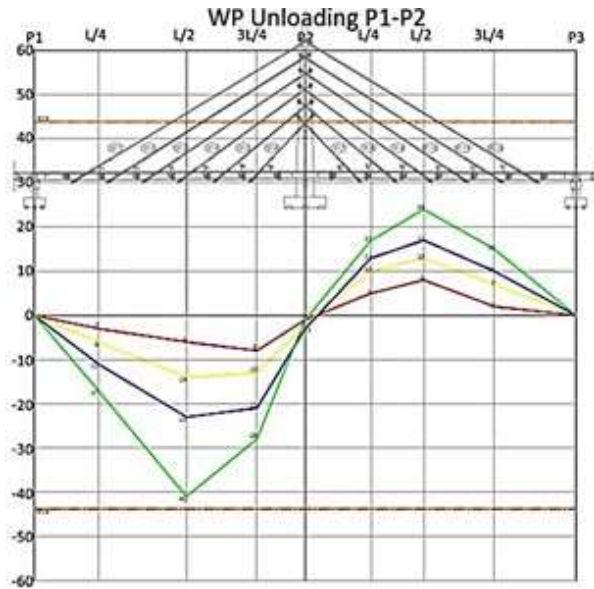

(b)

Figure 12. Graph of deflection measurement with waterpass when; a) loading and b) unloading span P1-P2 


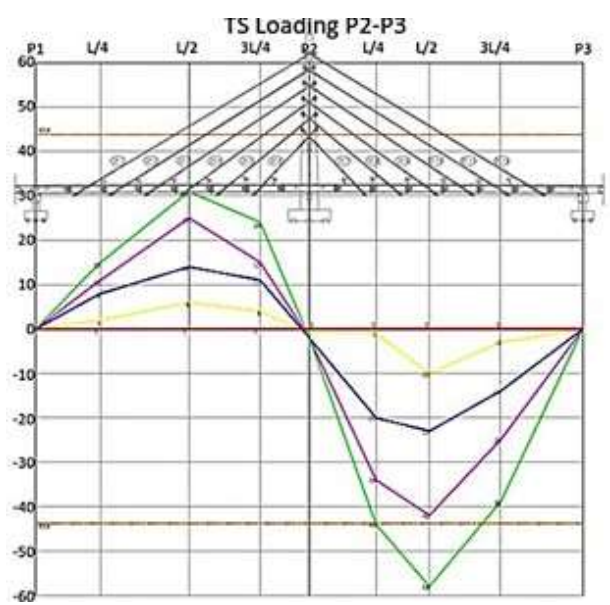

(a)

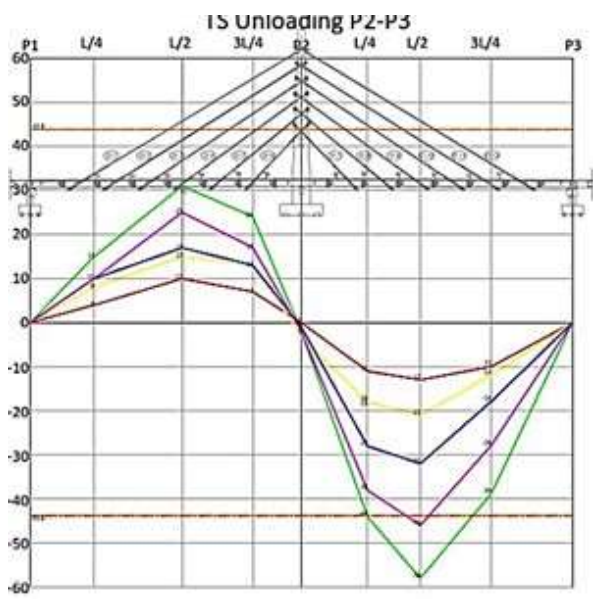

(b)

Figure 13. Graph of deflection measurement with total station when ; a) loading and b) unloading span P2-P3

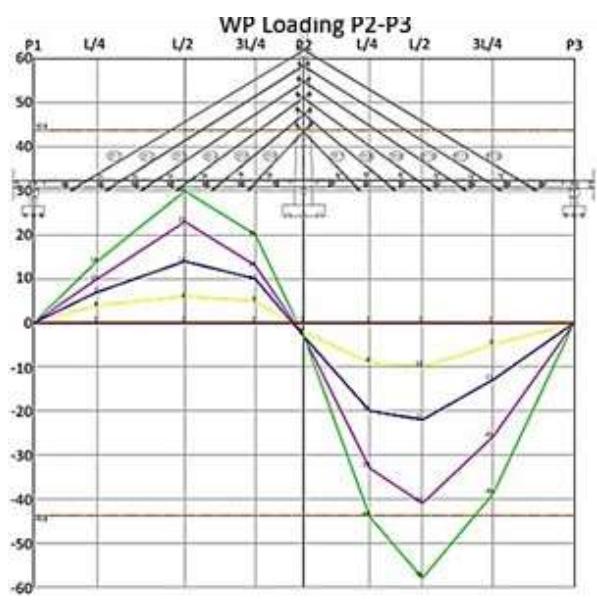

(a)

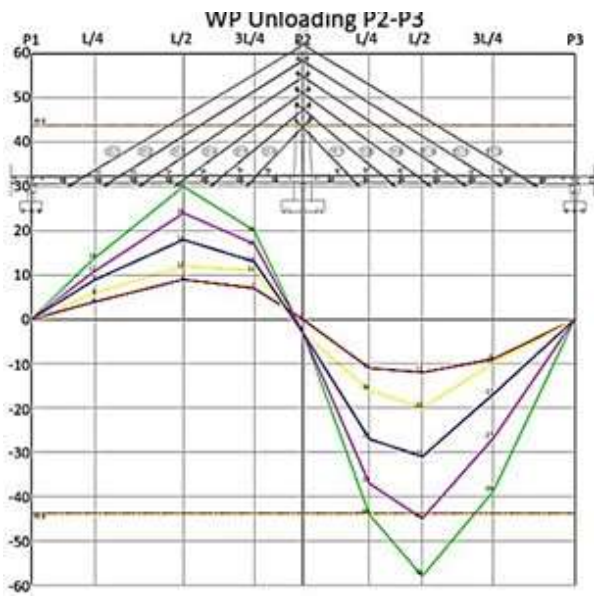

(b)

Figure 14. Graph of deflection measurement with waterpass when ; a) loading and b) unloading span P2-P3

\subsection{Result of dynamic load test}

Among the results obtained from dynamic testing is a graph of the acceleration versus time (time series) as shown in Figure 14 which is converted into the frequency domain with fast fourier transform (FFT) as shown in Figure 15. Based on one of these measurement results it is known that the natural frequency of the structure is $1.18 \mathrm{~Hz}$. Furthermore, the dynamic test results are compared with the theoretical frequency of the 3D modeling results as shown in Figure 16. Based on these comparisons it can be concluded that the structural model made in Midas Civil is in accordance with the results of tests carried out in the field with the natural frequency value in the first mode, namely $1.186 \mathrm{~Hz}$.
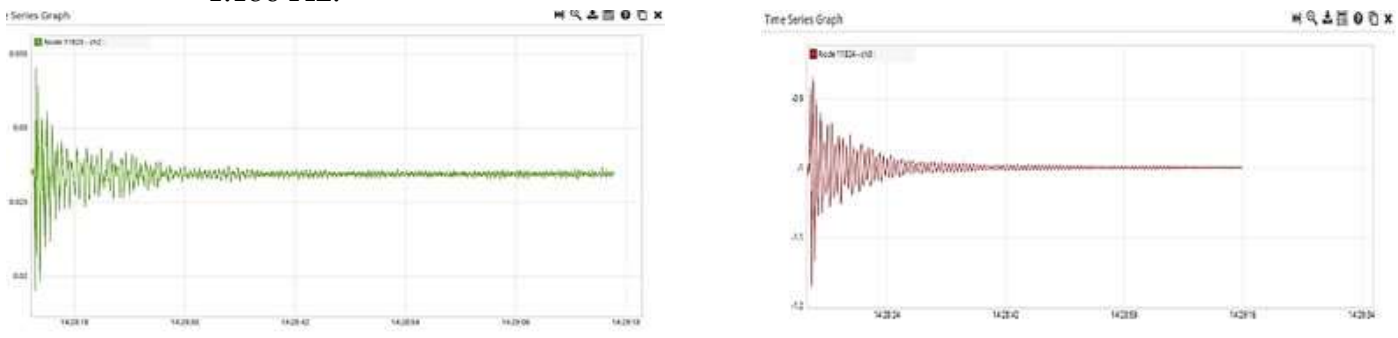
(a)

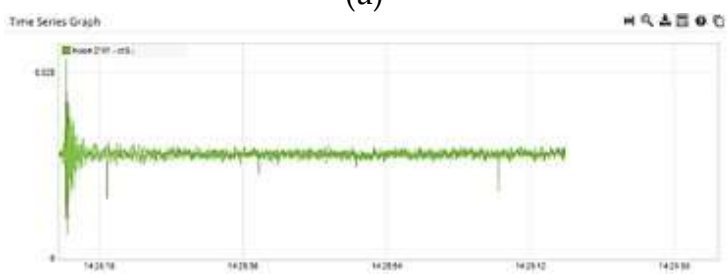

(c)

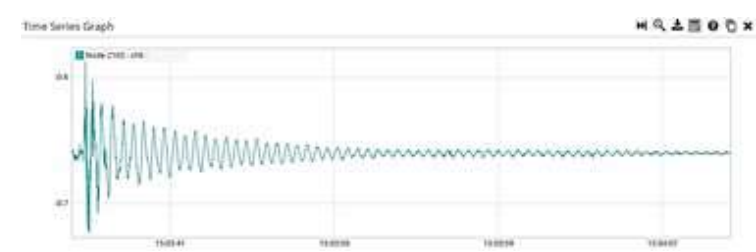

(e) (b)

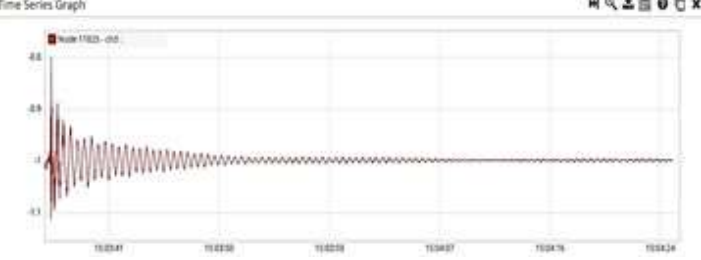

(d)

Figure 15. Graph of time series, a) transverse $1 \mathrm{~A}$; b) transverse $1 \mathrm{~B}$; c) transverse $1 \mathrm{C}$; d) transverse 2A; e) transverse $2 \mathrm{~B} ; \mathrm{f})$ transverse $2 \mathrm{C}$

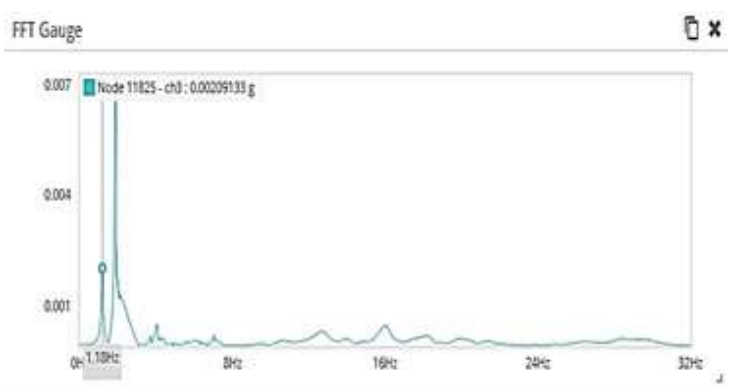

(a)

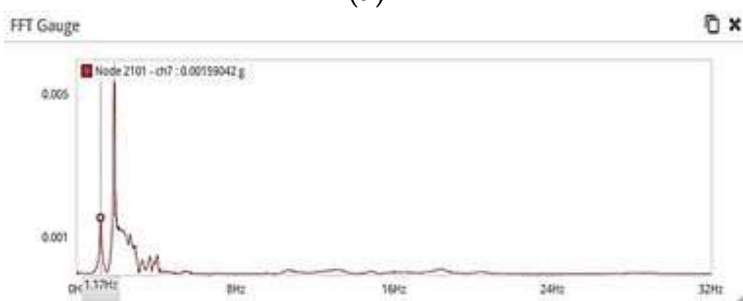

(c)

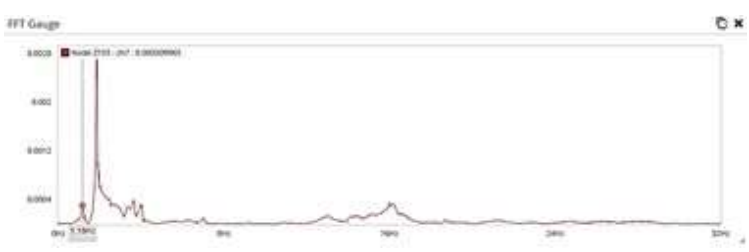

(e)

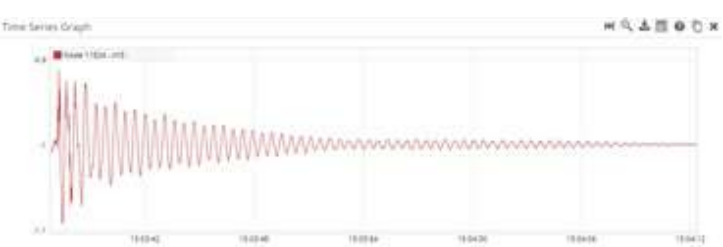

(f)

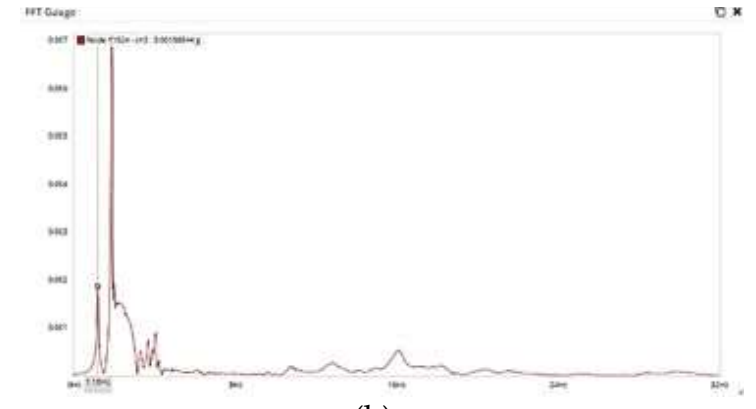

(b)

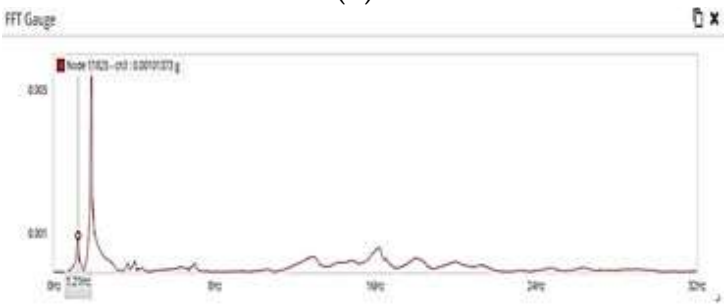

(d)

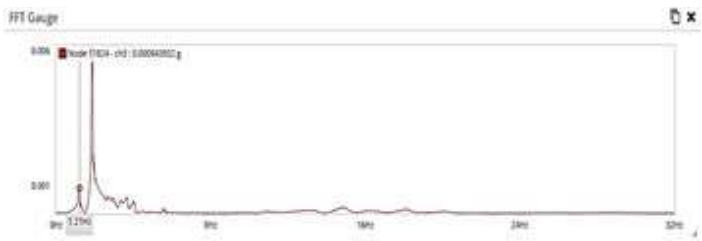

(f)

Figure 16. Graph of Fast Fourier Transform, a) transverse 1A; b) transverse 1B; c) transverse 1C; d) transverse 2A; e) transverse $2 \mathrm{~B}$; f) transverse $2 \mathrm{C}$ 


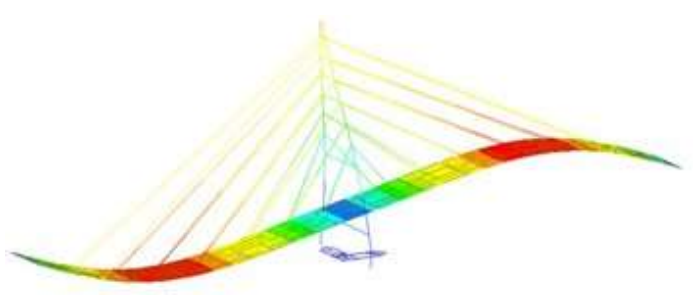

(a)

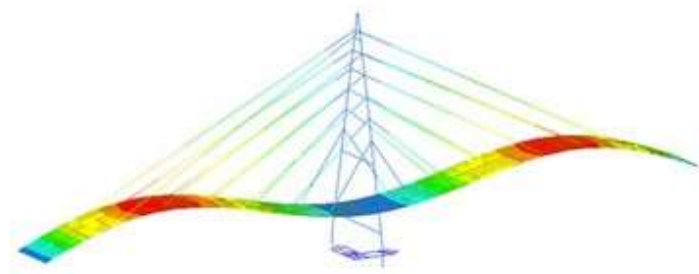

(b)

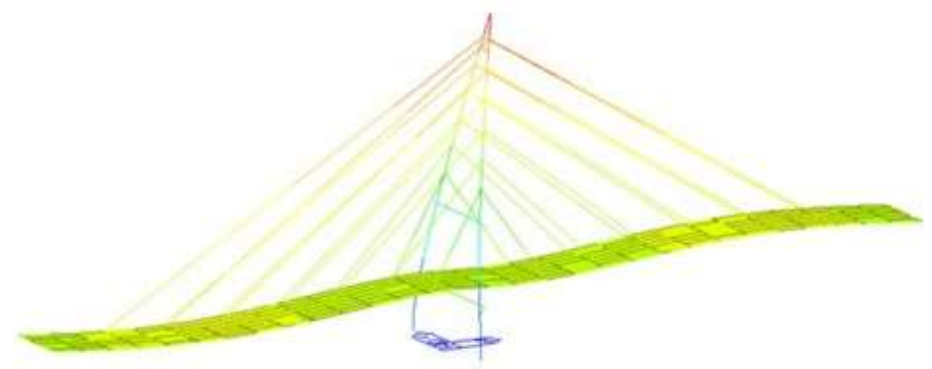

(c)

Figure 17. Mode shape of bridge with, (a) Mode $1 \mathrm{f}=1,186 \mathrm{~Hz}$; (b) Mode $2 \mathrm{f}=1,953 \mathrm{~Hz}$; (c) Mode $3 \mathrm{f}=2,608$

\section{Discussion}

\subsection{The cause of the explosion sound}

As in the previous description, it is known that during the loading of the 240-ton truck, a loud clanging sound was heard. Based on field observations, the sound comes from the stay cable. This sound is caused by an imperfect pulling of the strand during the construction period which causes the cable to stay in the tendon to fold. When the bridge is loaded, the strand is stretched so that what was originally folded straight back. The following is an illustration of this phenomenon as in Figure 18 below.

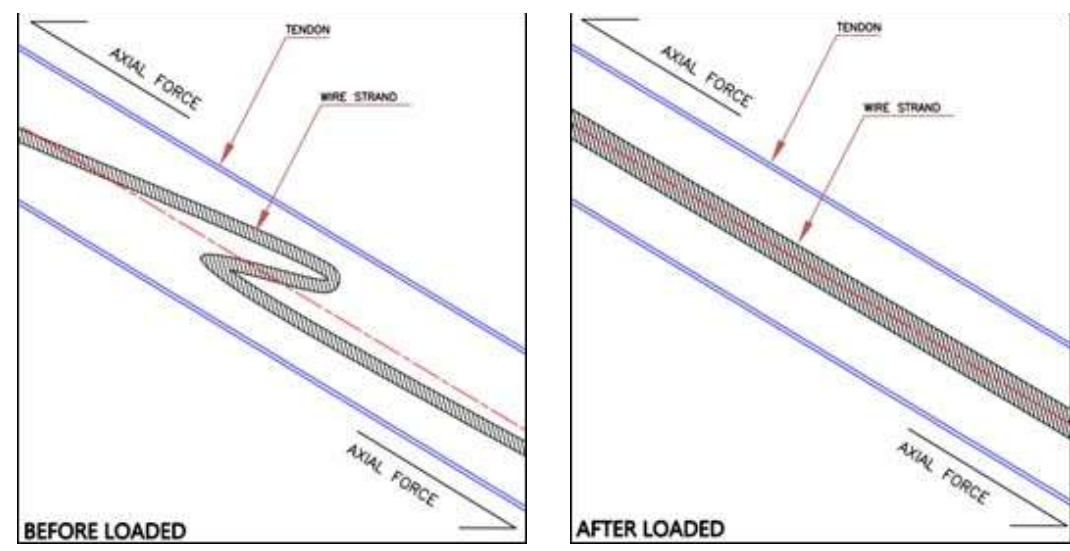

Figure 18. Condition of the strand before and after loaded by 240 ton truck

\subsection{Steel beam take a long time to return to an undeformed state}

Based on the phenomenon that occurs during load testing in the field, it is known that steel beams that deform when loaded require almost 24 hours to return to undeformed conditions. This is possible because of the effect of time dependent shortening on steel which depends on time. The creep condition is less likely to occur considering the ambient temperature when testing at normal temperatures [10]. 


\section{Conclusions}

The following is the conclusion from the description described in the previous section:

- The results of the static test were stopped at loads that were lower than planned, namely 240 tons from 300 tons and 480 tons from 600 tons due to deflection that was greater than permitted.

- Several dynamic tests show consistent natural frequency results, namely $\mathrm{f}=1.18 \mathrm{~Hz}$ for the first peak and $\mathrm{f}=1.88 \mathrm{~Hz}$ for the second peak.

- The dynamic tests carried out on the P1-P2 and P2-P3 spans also provide the same frequency for the two symmetrical spans.

- The results of the analysis give a natural frequency of $f=1.186444 \mathrm{~Hz}$ while the test gives a natural frequency of $f=1.18 \mathrm{~Hz}$. This shows that the structural model with Midas is in accordance with the measurement results in the field.

- Furthermore, on this bridge it is recommended to carry out continuous monitoring to measure deformation and stress at critical points.

Author Contributions: This work lead by Sumargo, he analyzed and load tested the cable stayed bridge in the field. Afdhal wrote the manuscript of journal.

Acknowledgments: This work supported by the Tujuh Pilar Hijau consultant company and organize by Ministry of Housing and Public Work.

Conflicts of Interest: The authors declare no conflict of interest

\section{References}

1. Chen, W.F. \& Duan, L. B. Bridge Engineering Handbook, 1st ed.; CRC Press, Washington, 1999; pp. 89-80

2. Bayraktar, A., Türker, T., Tadla, J., Kurşun, A., \& Erdiş, A. Static and dynamic field load testing of the long span Nissibi cablestayed bridge. Soil Dynamics and Earthquake Engineering 2017, 94, 136-157

3. Cunha, A., Caetano, E., \& Delgado, R. Dynamic tests on large cable-stayed bridge. Journal of Bridge Engineering, 2001, 6(1), 5462.

4. Ren, W. X., Peng, X. L., \& Lin, Y. Q. (2005). Experimental and analytical studies on dynamic characteristics of a large span cablestayed bridge. Engineering Structures, 2005, 27(4), 535-548.

5. Fang, I. K., Chen, C. R., \& Chang, I. S. Field static load test on Kao-Ping-Hsi cable-stayed bridge. Journal of Bridge Engineering, 2004, 9(6), 531-540.

6. Ni, Y. C., Zhang, Q. W., \& Liu, J. F. Dynamic property evaluation of a long-span cable-stayed bridge (Sutong bridge) by a Bayesian method. International Journal of Structural Stability and Dynamics, 2019, 19(01), 1940010.

7. Santoso, H. T. Penilaian Kondisi Jembatan Untuk Persyaratan Laik Fungsi Dengan Uji Getar. Portal: Jurnal Teknik Sipil, 2020, 12(1), 1-8.

8. Setiati, N. R., \& Surviyanto, A. Analisis Uji Beban Kendaraan Terhadap Jembatan Integral Penuh (Loading Test Analysis of Full Integral Bridge). Jurnal Teknik Sipil, 2013, 190-204.

9. Brownjohn, J. M., \& Xia, P. Q. Dynamic assessment of curved cable-stayed bridge by model updating. Journal of structural engineering 2000, 126(2), 252-260.

10. Kim, S. H., Park, S. Y., \& Jeon, S. J. Long-Term Characteristics of Prestressing Force in Post-Tensioned Structures Measured Using Smart Strands. Applied Sciences, 2020 10(12), 4084. 